\section{Court Reports}

Sir: During the last six years I have been a member of the Parole Board and thus a large number of prisoners' parole dossiers have passed through my hands. In a proportion of these cases psychiatric reports must have been available at the time of sentencing and yet they probably are never used beyond the Court hearing.

The position with regard to psychiatric reports is this: if there is a discretionary or mandatory life sentence, the Judge sends all the reports in his possession to the Home Office; such reports will then be quoted in the dossier or appear in full. However, where there is no life sentence but a period of years, the reports go no further than the Court. With more sentence planning being undertaken these latter reports could be of value to the prison; undoubtedly they are of value when the Parole Board are deciding whether to release or giving advice to the Home Office (the Parole Board has power to release between 4 and 7 years).

In recent years, when appropriate, I have taken to finishing my defence reports with an impartial sounding sentence along the following lines: "In the event of $X$ being made subject to a probation order, it would be of value if my report could be passed to the Probation Service. On the other hand if the Court decide a term of imprisonment is appropriate, then it would be of value if the defence solicitors, after consulting their client, could send a copy of this report to the Prison Medical Officer and also a copy to the Prison Welfare Officer (Probation Officer)".

Colleagues writing reports who do not already do this might consider it worthwhile to insert some similar sentence at the end of their reports.

I accept the reports may not always follow the prisoner but I know from my experience they do sometimes. Our profession has an important part to play in making the system work, particularly for life sentence prisoners who are beyond tariff. Deterrence and retribution have then been satisified and the issue is solely dangerousness. I would remind colleagues who are just starting out and writing such court reports to remember that they are not only writing their report for use in Court, but also for the benefit of those, who, many years later, have to address the question of safety to release.

I should add this letter is not addressed solely to forensic psychiatrists. One of the best reports that I have seen in the last year was written by a general psychiatrist with great clinical experience; members of the Parole Board praised the report for its valuable and useful insights. I regret to say that the worst report I have read in the last year was written by a forensic psychiatrist!

RoBert Reeves, Fromeside Clinic, Blackberry Hill, Stapleton, Bristol BS16 1ED

\section{The safest antidepressant(s) in epilepoy}

Sir: This is a subject that defies a simple straightforward response, thus, the clarification by Duncan \& Taylor (Psychiatric Bulletin, 1995, $19,355-357$ ) is most welcome. In the absence of double blind trial, information is largely empirical, gathered from clinical practice and the pharmacodynamic and pharmacokinetic properties of individual antidepressants.

The findings so far are sometimes conflicting and at best, broad guidelines are given to assist in determining the choice of antidepressant for an eplleptic. The situation is further compounded by the fact that patients often take more than one anticonvulsant and are on other psychotropic medication as well, with the potential of drug interactions that are highly variable and unpredictable.

In the Psychotropic Drug Directory (Bazire, 1995), amoxapine and maprotiline are listed as constituting high risk potential for seizures. There is a consensus about the high risk of these two antidepressants and the fact that MAOIs are probably the safest. In quoting Rosenstein et al (1993) and Showron \& Stimmel (1992) and in their summary, the authors mention fluoxetine first as antidepressant of choice in terms of relative safety in epilepsy. While I am convinced that this is an alphabetical rather than a safety rating, I think it is pertinent to note that, according to the Psychotropic Drug Directory, fluoxetine has been reported to be associated with more seizures than other SSRIs. The authors also state that trazodone and sertraline may be less likely to interact with anticonvulsants. May I also point out that, according to manufacturer's information, paroxetine also does not interact with anticonvulsants.

Thus, each patient with epilepsy requires an individualised assessment and close monitoring regarding all relevant issues mentioned in the paper, recognising that there is a dosedependent relationship between antidepressant drugs and seizures, and also taking into 
consideration risk factors, which for example in mianserin are reported to include a family history of epilepsy, starting treatment or changing doses (Bazire, 1995).

Bnzare, S. (1995) Psychotropic Drug Directory.

Rosenstren, D. L., Nerson, J. C. \& Jacobs, S. C. (1993) Seizures assoctated with antidepressants: a review. Joumal of Clinical Psychiatry, 84, 89-99.

Showron, D. M. \& Stmagh, G. L. (1992) Antidepressants and the risk of selzures. Pharmacotherapy. 12. $18-22$.

R. A. ADENIRAN, University of Wales College of Medicine, Academic Sub-department of Psychological Medicine, North Wales Hospital, Denbigh, Cluyd LL16 5SS

\section{Mental Bealth Review Tribunals}

Sir: Following my earlier letter about Mental Health Review Tribunals (Psychiatric Bulletin, 1995, 19, 258), I am happy to report that the Lord Chancellor's Department have agreed to relax the rules for the first appointment of medical members to the Mental Health Review Tribunal. They have agreed that the upper age limit for a first appointment may be 65 on the condition that candidates can produce evidence of recent employment, although it need not be continuous.

I have also been asked to point out that the Department of Health will only appoint a doctor able to give limited commitment in exceptional circumstances. The normal commitment for members is between 20-50 days a year; 70 days for retired members.

This is a significant improvement on the previous situation and may go some way towards improving the recruitment and thereby the standard of medical work within the tribunal system.

JoHn GunN, Professor of Forensic Psychiatry, Institute of Psychiatry, De Crespigny Park, Denmark Hill, London SE5 8AF

\section{Trainee pejchiatrists' theoretical vacuum}

Sir: Standards of research carried out by trainee psychiatrists continue to attract debate (Owens, House \& Worrel, Psychiatric Bulletin, $1995,19,337-339$ ) with the emphasis on ways of improving standards, a trend which receives much support from the Royal College. Rarely is the question asked whether research among trainees is desirable.

I have felt impelled to undertake research projects to progress my career. On the whole these were projects I was not interested in and were done for the sole purpose of securing a Senior Registrar post. From talking to other colleagues this is a very common experience. Owens et al emphasise proper supervision giving trainees a greater understanding of methodological issues and clinical epidemiology. While I do not question the importance of understanding research in psychiatry, little consideration is given to the importance of developing theoretical understandings that allow the trainee to question and criticise the scientific assumptions made by researchers. Vast amounts of research tend to take place in a theoretical vacuum, and have little influence on clinical practice.

Psychiatry's scientific framework and categorical validity rests on an idea of common consensus, as opposed to discretely measurable phenomena. This is subjective but research creates an illusion that our categories are scientific and objective.

Juniors training in psychiatry have a vast amount to learn. The time and money spent on finding and devising research projects of questionable usefulness could be better spent understanding and training in the more subjective aspects of psychiatry such as encouragement and support for a psychotherapeutic qualification, and perhaps exposure to personal therapy. This is the case in other European countries. The emphasis on research experience at a junior level of a psychiatrist's career runs the risk of the new generation of psychiatrists being encouraged to become academically knowledgeable at the expense of being technically and therapeutically competent.

S. TMmmI, Senior Registrar, Child and Adolescent Psychiatry, Great Ormond Street Hospital For Children, London WC1N 3JH

\section{Corrigendum}

In Milton's letter (Psychiatric Bulletin, 19, 575576) "above BNF limits" for chlorpromazine are $1000 \mathrm{mg}$. 